\title{
Carácter moral y deberes éticos
}

\author{
FAVIOLA RIVERA CASTRO \\ Instituto de Investigaciones Filosóficas, UNAM, México
}

RESUMEN. Los defensores de la ética de la virtud usualmente califican a la ética kantiana como una moralidad centrada en el acto porque, sostienen, su principal objeto de evaluación moral son los actos particulares, con lo cual un acto puede ser moralmente bueno a pesar de que el carácter de quien lo lleva a cabo no sea virtuoso. Sostienen que, por el contrario, la ética debe centrarse en el carácter de las personas, de modo que un acto es moralmente valioso sólo cuando es la expresión de un carácter virtuoso. El propósito de este artículo es mostrar que, en contra de lo que sostienen los partidarios de la ética de la virtud, el principal objeto de evaluación moral en la ética kantiana es el carácter de las personas. El imperativo categórico no exige la realización de actos particulares, sino la adopción de máximas de fines, las cuales son principios para una vida completa. Sostengo que la adopción de estas máximas necesariamente requiere la adquisición de un carácter virtuoso, de tal modo que quien se compromete sinceramente con los principios éticos lleva a cabo acciones buenas y tiene también un carácter moral.

La ética de la virtud usualmente se presenta como una alternativa superior a las teorías morales kantianas y utilitaristas con el argumento de que considera el carácter de los agentes como el objeto principal de evaluación moral, mientras que las segundas se centran en la corrección de los actos particulares. La supuesta superioridad se basa en que si nos centramos en la evalua-
ABSTRACT. Proponents of virtue ethics usually charge Kantian ethics with being act-centered because, they claim, its main object of moral evaluation are particular acts. This has the unwelcome consequence that an act can be morally worthy though the character who performs it is not virtuous. They also claim that ethics should focus on the character of persons such that only those acts that are the expression of a virtuous characters can be morally good. My purpose in this article is to show that the main object of moral evaluation in Kantian ethics is the character of persons. The categorical imperative does not demand the performance of particular acts, but the adoption of maxims of ends, which maxims are principles to guide a complete life. I claim that the adoption of such maxims necessarily requires the acquisition of a virtuous character so that whoever commits herself to living according to ethical principles both performs good acts and acquires a virtuous character.

ción de actos particulares, un acto puede ser correcto a pesar de que el agente que lo lleva a cabo tenga un carácter moralmente malo, lo cual es insatisfactorio. Piénsese, por ejemplo, en el mentiroso compulsivo que es capaz, en cierta ocasión afortunada, de sobreponerse a su inclinación a mentir y dice la verdad porque lo considera su deber; su acto de veracidad 
será moralmente correcto aunque su carácter siga siendo malo. En cambio, si tomamos el carácter como el objeto principal de evaluación moral, las acciones moralmente buenas serán aquellas realizadas por personas virtuosas, en cuyo caso ya no surge la posibilidad de elogiar el acto y reprobar el carácter al mismo tiempo. Desde este punto de vista, un acto moralmente correcto llevado a cabo por alguien con un carácter moralmente deficiente es por ello también moralmente deficiente. Como los kantianos y los utilitaristas supuestamente se centran en los actos particulares como el objeto principal de evaluación moral, un acto correcto no puede ser moralmente deficiente aunque la persona que lo realiza tenga un carácter moralmente malo. La objeción contra las así llamadas «moralidades del acto» es que pierden de vista la importancia del carácter en la evaluación moral porque sistemáticamente subordinan el valor del carácter al valor de los actos particulares ${ }^{1}$.

En lo que sigue voy a asumir que los defensores de la ética de la virtud tienen razón al afirmar que la teoría moral debe centrarse en el carácter de las personas como el objeto principal de evaluación moral. Comparto con ellos la intuición de que cuando un acto moralmente correcto es realizado por una persona con un carácter moralmente deficiente, el acto mismo tiene que ser deficiente también. Voy a sostener, sin embargo, que la ética kantiana no es una moralidad del acto, al menos no en el sentido criticado por los defensores de la ética de la virtud ${ }^{2}$. En mi interpretación, la ética kantiana también considera al carácter de los agentes como el objeto principal de evaluación moral. Para defender esta tesis voy a proceder en dos pasos. Primero mostraré que el contenido de las exigencias éticas no es la realización u omisión de actos particulares, sino la adopción de máximas moralmente buenas. En un segundo paso veremos que dicha adopción necesariamente requiere la adquisición de un carácter virtuoso.

En el primer capítulo de la Fundamentación para una metafísica de las costumbres ${ }^{3}$ Kant sostiene que el objeto de evaluación moral es la máxima de la acción y sostiene que una máxima moralmente meritoria es aquella que podemos querer como ley universal. Las máximas son aquellos principios con base en los cuales una persona actúa; por ello, Kant se refiere a ellas como «principios subjetivos» (FMC, Ak. IV , 401n). No obstante, como lo mencioné en la introducción, es muy común pensar que el objeto de evaluación moral en la moralidad kantiana son las acciones. La razón de ello es que Kant se refiere a las acciones particulares como moralmente buenas cuando las máximas en que se basan también lo son. Pero deja muy clara la relación de prioridad: el valor moral de una acción depende del valor moral de la máxima. Por tanto, el imperativo categórico exige que actuemos con base en ciertas máximas, esto es, aquellas que podamos querer como leyes universales.

Dos de los ejemplos explícitos de máximas que aparecen en la Fundamentación son los siguientes: «En base al egoísmo adopto el principio de abreviarme la vida cuando ésta me amenace a largo plazo con más desgracias que amenidades prometa» (FMC, Ak. IV, 422). «Cuando me crea sumido en un apuro económico, pediré dinero a crédito y prometeré devolverlo, aunque sepa que nunca sucederá tal cosa» (FMC, ibid.). En ambos casos le interesa mostrar que estas máximas no son moralmente aceptables porque, sostiene, no son universalizables. Estos ejemplos dejan claro que una máxima es un principio o regla para la realización de un cierto tipo de acciones, y no meramente para una acción específica irrepetible. También es manifiesto que la 
máxima especifica un tipo de acto («abreviar la vida», «prometer devolver un crédito») a realizar por alguna razón, fin o motivo («cuando las desgracias superen a las amenidades», «pedir dinero a crédito»). Lo que quiero destacar es que las máximas no especifican únicamente el tipo de acto externo a realizar, sino que contienen también las razones, motivos o fines por los cuales tales actos se llevan a cabo. Este punto surge claramente en el primer capítulo de la Fundamentación cuando Kant compara las acciones de un filántropo en dos momentos de su vida: primero, el filántropo ayuda por inclinación y, después, por deber. Los actos externos del filántropo son los mismos, a saber, ayudar, pero Kant sostiene que sólo la segunda acción tiene valor moral porque, nos dice, sólo en el segundo caso la máxima es moralmente meritoria. Las máximas, entonces, contienen las razones, motivos o fines por las cuales se actúa, y el mismo acto externo puede llevarse a cabo con base en máximas diferentes.

Sobre las máximas también es importante mencionar que no tienen por qué ser explícitas en el momento de la acción. La tesis de Kant es que toda acción se realiza con base en alguna máxima, pero éstas, en la gran mayoría de los casos, están implícitas, y en algunos de ellos podemos reconstruirlas a partir de lo que hacemos y de nuestras motivaciones. Pero en muchas situaciones, precisamente porque nuestros motivos son opacos, también lo son las máximas. Esto no representa un problema para Kant porque a él le interesa establecer las máximas con base en las cuales debemos actuar. La evaluación de la conducta pasada o ajena no figura de manera importante en su teoría.

Esta aclaración sobre las máximas sirve para rechazar la creencia de que el objeto principal de evaluación moral en la ética kantiana son los actos particulares. Sin embargo, no es suficiente para responder satisfactoriamente a los defensores de la ética de la virtud. En primer lugar, una persona puede actuar con base en máximas moralmente buenas en ciertas ocasiones a pesar de que su carácter sea moralmente deficiente. Piénsese de nuevo en el mentiroso compulsivo que es capaz de decir la verdad en ciertas ocasiones por el motivo del deber. De acuerdo con Kant, actuar por el motivo del deber es verse movido por el pensamiento de que la moralidad exige la acción. En este caso, el mentiroso es capaz de actuar con base en una máxima moral (una máxima de deber) a pesar de que su carácter es moralmente deficiente. Esto sugiere que, al menos indirectamente, la ética kantiana le otorga prioridad al valor moral de las acciones por encima del valor del carácter. En segundo lugar, al sostener que las máximas son el principal objeto de evaluación moral, Kant deja de lado a los sentimientos, a los que considera carentes de valor moral ${ }^{4}$. Deja muy claro que el valor moral de una acción guiada por una máxima moralmente buena no se ve afectada en lo más mínimo, ni de manera positiva ni negativa, por los sentimientos e inclinaciones que se experimentan $(F M C, 4$, 398-399). El valor moral reside en lo que el agente se determina a hacer, no en los sentimientos e inclinaciones que, según Kant, tienen lugar en él y respecto de los cuales es pasivo. En la sección sobre el sentimiento moral en la Introducción a Principios Metafisicos de la Doctrina de la Virtud ${ }^{5}$ señala que «no es conveniente llamar a este sentimiento sentido moral porque con el término "sentido" se entiende por lo común una facultad teorética perceptiva, referida a un objeto; por el contrario, el sentimiento moral (como el placer y el desagrado en general) es algo meramente subjetivo, que no suministra conocimiento» (PMDV, Ak. VI, 400). El hecho de que el mentiroso compulsivo tenga que superar su fuerte inclinación a mentir no le resta nada al valor moral de su acción de decir la verdad por deber. La 
razón es que como la inclinación no es una forma de percepción o conocimiento de los rasgos morales de la situación en la que se encuentra, sino algo meramente subjetivo, no afecta en nada al valor moral de su comportamiento.

Un ejemplo del propio Kant es su segunda versión del filántropo que ayuda al prójimo por deber. Ahora nos pide que imaginemos al filántropo como una persona «fría e indiferente al dolor ajeno». Presenta su ejemplo de tal modo que la persona ayuda a otros a pesar de que no experimenta ningún sentimiento que lo podría mover a ayudar. El punto que le interesa enfatizar es que el valor moral de una acción reside en la máxima: siempre que la persona actúe según una máxima moralmente buena (tal como «ayudar a otros porque es mi deber»), su acción será moralmente meritoria al margen de los sentimientos que exprese o deje de expresar. Pero esto es precisamente lo que rechazan los partidarios de la ética de la virtud, ya que consideran que los sentimientos tienen valor moral y que, por tanto, son objetos apropiados de evaluación moral. Esta perspectiva tan diferente sobre los sentimientos se debe a que, a diferencia de Kant, se les considera modos de percepción sobre los aspectos moralmente relevantes de las acciones o estados de cosas. En el caso del filántropo, su indiferencia frente al dolor ajeno es reprobable moralmente porque esta actitud es un modo de percibir la situación de los demás: al reaccionar con indiferencia, el filántropo percibe el dolor ajeno como algo que no tiene por qué moverlo a hacer nada; o más bien, al reaccionar con indiferencia el filántropo no percibe el dolor ajeno como una razón para ayudar. Si los sentimientos son modos de percepción, entonces pueden ser apropiados o inapropiados. Desde este punto de vista, alguien que cumpla con su deber, pero experimente sentimientos que son contrarios a su convicción moral y a los que tiene que sobreponerse, muestra una falta de armonía entre la razón y los sentimientos: mientras la razón le indica que debe ayudar, sus sentimientos le dicen que no tiene porqué hacerlo. Según los partidarios de la ética de la virtud, esta armonía es precisamente la característica de un carácter virtuoso y quien carezca de ella posee un carácter moralmente deficiente.

Para ofrecer una respuesta más adecuada a los críticos será necesario considerar con más detenimiento el contenido de los deberes éticos, así como la función de los sentimientos morales en la práctica de la virtud. Mi objetivo es mostrar que la ética kantiana exige algo más que la mera realización de acciones moralmente meritorias, a saber, la adquisición de un carácter moral, y que este último se caracteriza, en parte, por la presencia de ciertos sentimientos morales.

\section{2}

La idea de que la moralidad kantiana se centra en los actos particulares como el objeto principal de evaluación moral a expensas del carácter de los agentes se debe también a la tendencia a confundir las exigencias de la ética y las de la justicia. Kant divide los deberes morales en deberes de virtud (o éticos) y de justicia (o jurídi$\cos )^{6}$. Los deberes éticos constituyen el dominio de lo que podemos llamar «moralidad personal», mientras que los de justicia son aquellos que la autoridad política se encarga de hacer valer por medios coactivos. Distingue entre los deberes éticos y los jurídicos de acuerdo con el tipo de legislación. Sostiene que toda legislación tiene dos elementos: una ley que representa una acción como objetivamente necesaria y un incentivo que constituye el elemento subjetivo en la determinación a la acción exigida por la ley ( $P M D V$, Ak. VI, 218). Nos dice que, en consecuencia, toda legislación puede distinguirse por el incentivo: la legislación «que hace de 
una acción un deber y de ese deber, a la vez, un incentivo es ética», mientras que la legislación «que no incluye al último en la ley y, por tanto, admite también otro incentivo distinto de la idea misma del deber es juridica» ( $P M D V, 6,219)$. A primera vista parece que la diferencia entre los deberes éticos y los jurídicos reside en que los primeros exigen la realización de ciertos actos por incentivos morales, en tanto que los segundos permiten cualquier tipo de incentivo, sea moral o bien de la inclinación.

Esta manera de expresar la distinción entre los deberes éticos y los jurídicos apoya la tesis de que tanto la ética como la justicia exigen la realización u omisión de actos particulares, y que sólo se distinguen en que la ética además exige motivos morales. Sin embargo, en la Introducción a Principios metafísicos de la doctrina de la virtud Kant sostiene que los deberes jurídicos son de obligación estricta porque exigen acciones (a realizar u omitir), mientras que los deberes éticos son de obligación amplia porque exigen la adopción de máximas de fines pero no especifican qué debamos hacer en particular para cumplirlos ${ }^{7}$. Sobre los deberes amplios nos dice lo siguiente: «Si la ley sólo puede ordenar la máxima de las acciones, no las acciones mismas, esto es un signo de que deja un margen (latitudo) al arbitrio libre para el cumplimiento (la observancia), es decir, que no puede indicar con precisión cómo y cuánto se debe obrar con la acción con vistas al fin que es a la vez un deber. Pero por deber amplio no se entiende un permiso para introducir excepciones a la máxima de las acciones, sino sólo el de limitar una máxima del deber por otra (por ejemplo, el amor universal al prójimo por el amor paternal), con lo cual se amplía realmente el campo de la praxis virtuosa» (PMDV, Ak. VI, 390)

Un deber que exige la adopción de un fin deja mucho margen para determinar qué acciones llevar a cabo con miras a su cumplimiento. Los deberes son estrictos, en cambio, cuando la ley exige actos particulares pero no máximas. Por ejemplo, el deber de hacer el bien es ético porque exige la adopción del fin de ayudar a los demás como algo valioso en sí mismo, sin especificar qué acciones en particular se deben llevar en cabo; en cambio, el deber de cumplir los contratos es estricto porque exige la realización del acto externo sin importar el motivo.

Kant también divide los deberes morales en perfectos e imperfectos. Sobre ellos nos dice que únicamente los deberes de virtud pueden ser imperfectos y que su cumplimiento es meritorio, mientras que dejar de observarlos no es demérito, sino únicamente falta de valor moral ( $P M D V$, Ak. VI, 390). Esto sugiere que el cumplimiento de los deberes perfectos no es meritorio y que su omisión implica culpabilidad. Es muy común en la literatura tratar como equivalentes las distinciones estricto/amplio y perfecto/imperfecto. Usualmente se asume que «amplio» significa lo mismo que «imperfecto» y que este tipo de deberes permiten cierto margen para decidir qué hacer con miras a su cumplimiento ya que exigen la adopción de máximas de fines; como no exigen ninguna acción en particular, se supone que su cumplimiento es meritorio. También se piensa que los deberes que exigen actos particulares a realizar u omitir son perfectos o estrictos y que, por ello mismo, su cumplimiento no es meritorio sino debido $^{8}$. De acuerdo con esta lectura, todos los deberes de virtud son amplios e imperfectos, y todos los jurídicos son perfectos y estrictos. La dificultad, sin embargo, es que Kant sugiere en varios lugares que tenemos deberes éticos perfectos.

En la Principios metafísicos de la doctrina de la virtud encontramos que el fin ético de promover la propia perfección da lugar tanto a deberes perfectos como imperfectos. Dentro de los primeros Kant menciona el deber negativo de no suici- 
darse, y entre los segundos se encuentra el deber de cultivar los talentos y capacidades naturales. De manera paralela, el fin ético de promover la felicidad de los demás da lugar a dos tipos de deberes: los de amor y los de respeto. Dentro de los primeros encontramos el deber de hacer el bien y de fomentar el sentimiento de la simpatía hacia las necesidades ajenas; y dentro de los segundos están los deberes negativos de evitar vicios como la arrogancia. Si bien no dice que los deberes de amor sean imperfectos y los de respeto perfectos, sí lo sugiere cuando afirma que «la omisión de los deberes de amor, simplemente, es falta de virtud (peccatum). Pero la omisión del deber que surge del respeto debido a cada hombre en general es un vicio (vitium). Porque olvidando los primeros no se ofende a hombre alguno; mientras que la omisión de los segundos daña al hombre en su legítima pretensión» (PMDV, Ak. VI, 464).

En vista de la existencia de los deberes éticos perfectos es necesario ofrecer una caracterización de la distinción perfecto/ imperfecto que sea independiente del par estricto/amplio. Para los fines de este trabajo este punto cobra cierta importancia porque quienes suscriben la equivalencia de las dos distinciones suponen que cuando un deber es perfecto no se exige la adopción de ninguna máxima aunque se trate de un deber ético. Por ejemplo, Thomas Hill sostiene que los deberes perfectos exigen la realización de actos particulares, pero no la adopción de alguna máxima y que, por tanto, «uno podría observar un deber perfecto llevando a cabo el tipo correcto de acto sin haber adoptado ningún principio relevante para la situación, pero uno no podría observar un deber imperfecto de la misma manera» ${ }^{9}$. Me interesa rechazar esta postura porque la afirmación de que algunos deberes éticos, por ser perfectos, exigen la realización u omisión de actos particulares sin importar la máxima apoya la tesis de que la ética kantiana, al menos parcialmente, se centra en los actos y no en el carácter. Para sostener que, por el contrario, el principal objeto de evaluación en la ética kantiana es el carácter de las personas es necesario mostrar que la ética siempre exige la adopción de máximas de fines, aun en el caso de deberes que exijan la realización u omisión de acciones específicas.

Con el fin de separar los dos pares de categorías de deberes propongo la caracterización siguiente. La distinción amplio/estricto claramente concierne al contenido del deber: o bien el deber exige la adopción de una máxima de fin, o bien la realización u omisión de algún acto particular sin importar la máxima. Esto concuerda con la afirmación de Kant de que los deberes éticos siempre son amplios porque exigen la adopción de máximas, mientras que los jurídicos son estrictos porque se limitan a prescribir o prohibir actos particulares. Como también sostiene que sólo los deberes de virtud o éticos pueden ser imperfectos, entonces todos los deberes jurídicos son perfectos, mientras que los de virtud pueden ser perfectos o imperfectos. Esta segunda distinción parece referirse al beneficiario del deber, es decir, a si el deber se le debe a alguien en particular o no. Kant dice que el cumplimiento de un deber imperfecto es meritorio, mientras que su omisión no implica culpabilidad sino falta de valor moral Para que la omisión de un deber imperfecto no implique culpabilidad tiene que tratarse de un deber que no se le deba a alguien en particular. Como él mismo lo señala, «olvidando los primeros no se ofende a hombre alguno». Por ejemplo, el deber de hacer el bien es imperfecto porque su cumplimiento no se le debe a nadie en particular: a quién ayudar, cuándo y de qué manera se le deja al arbitrio de cada persona. En cambio, la omisión de un deber perfecto sí implica culpabilidad precisamente porque hay alguien en particular a quien su cumplimiento se le debe $y$, 
puede, por tanto, exigirlo en caso de omisión. Esto no significa que siempre se trate de una persona específica exclusivamente. Hay deberes perfectos que se le deben a cada persona en particular porque su omisión implicaría tratarlos como meros medios. Kant señala que «la omisión de los [deberes de respeto] daña al hombre en su legítima pretensión», los cuales son deberes que se le deben a cada persona en particular. Aquellos deberes que se le deben a un individuo en específico exclusivamente son las obligaciones incurridas, tales como el cumplimiento de las promesas y los contratos. Esto concuerda con su tesis de que el cumplimiento de los deberes imperfectos es meritorio: como se le debe ayuda a nadie en particular, la conducta es meritoria cuando se ayuda a alguien, pero no hay culpa cuando se deja de hacerlo; y como se le debe respeto a todos, la actitud correspondiente no puede ser meritoria, mientras que la falta de respeto implica culpabilidad.

Esta doble distinción tiene dos implicaciones incómodas que debo mencionar. En primer lugar, resulta extraño que el deber de cultivar los talentos, por ser imperfecto, no nos lo debamos a nosotros mismos. El deber es amplio, por ser ético, lo cual significa que se exige la adopción de la máxima, pero no la realización de alguna acción en particular. Como el único beneficiario de un deber hacia uno mismo somos nosotros mismos, parece que tendría que ser perfecto. Sin embargo, Kant parece suponer que el desarrollo de la propia perfección natural es hacer más por nosotros mismos de lo que estrictamente nos debemos; por ello, el cumplimiento de este deber es meritorio. Esto se debe a su tesis de que la humanidad es un fin negativo, es decir, un fin contra el cual no debemos actuar nunca. Estrictamente, lo que nos debemos a nosotros mismos y a los demás es abstenernos de tratar a la humanidad propia y ajena de maneras que sean incompatibles con su valor incondicionado. En cambio, ayudar a los demás en la consecución de sus fines y cultivar los talentos y capacidades propias es, según Kant, hacer algo más de lo estrictamente debido a la humanidad concebida como fin negativo, y es por ello meritorio.

La segunda implicación proviene de la manera en que Kant concibe los deberes imperfectos. Como vimos, nos dice que su observancia es meritoria, en tanto que dejar de cumplirlos no implica culpabilidad. Sin embargo, algunos tipos de acciones que caen claramente bajo los deberes imperfectos parecen ser obligaciones más perfectas. No es lo mismo dejar de ayudar al extranjero que vive en algún lugar remoto, que al vecino que acaba de sufrir un accidente doméstico y nos pide auxilio. Si bien tenemos el deber de ayudar al prójimo en general, tenemos la libertad de decidir a quién ayudar, cuándo y de qué manera, y los criterios obvios para hacer estas elecciones parecen ser la proximidad, la urgencia de la necesidad ajena, y las relaciones especiales que mantenemos con ciertas personas. Es natural que la presión para ofrecer ayuda resulte mayor cuando se trata de alguien cercano, como el vecino, que cuando el necesitado es un extranjero en un país remoto. No obstante, Kant sugiere que en ningún caso tenemos una obligación perfecta, aunque el ejemplo del vecino muestra que dejar de cumplir con un deber imperfecto a veces sí puede implicar culpabilidad. Pienso que no es posible resolver esta dificultad si nos mantenemos dentro de lo que Kant sostiene explícitamente, pero la labor de interpretación necesaria para aclarar este punto rebasa los límites de este trabajo.

Lo que a mí me interesa establecer es que los deberes éticos, a diferencia de los jurídicos, son amplios; lo cual significa que siempre exigen la adopción de una máxima, sea que se trate de un deber perfecto o de uno imperfecto. En ambos casos es imposible satisfacer las exigencias de la 
ética si no se actúa con base en una máxima de fin. Aun en el caso de los deberes éticos negativos, como no suicidarse y no tratar a los demás con arrogancia, la exigencia no es meramente abstenerse de realizar los actos externos correspondientes. $\mathrm{El}$ deber exige ciertamente abstenerse de realizar ciertos actos externos, pero en el medida que es ético, la omisión debe basarse en una máxima de fin, la cual especifica las consideraciones éticas por las cuales tales actos no deben llevarse a cabo. Tanto en el caso del suicidio, como en el de la arrogancia, se exige que actuemos movidos por una actitud valorativa hacia nosotros y hacia los demás, respectivamente. No es suficiente no suicidarse por temor a la muerte: uno debe preservar la propia vida porque se valora a sí mismo como un fin incondicionado. Igualmente, se debe evitar la arrogancia en el trato con los demás movidos por el reconocimiento del valor incondicionado de la humanidad en otras personas. Esto último es claro cuando Kant sostiene que el sentimiento de respeto acompaña el cumplimiento de los deberes de respeto hacia los demás (PMDV , 6, 448).

Hasta ahora hemos visto que la ética kantiana no exige la mera realización $u$ omisión de actos externos, sino la adopción de máximas de fines. A continuación veremos por qué esta adopción necesariamente requiere el desarrollo de un carácter moral y por qué, debido a ello, este último es el principal objeto de evaluación moral.

\section{3}

A diferencia de la Fundamentación, en donde el énfasis recae en el mérito moral de acciones particulares, en Principios metafísicos de la doctrina de la virtud Kant deja claro que la adopción de máximas de fines éticos es un proyecto a largo plazo ${ }^{10}$. La exigencia ética no es actuar con base en estas máximas en ciertas ocasiones, sino adoptarlas como principios firmes a lo largo de una vida completa, lo cual supone la práctica constante de las acciones exigidas por las máximas. Lo que me interesa destacar es que esta práctica, si es exitosa, tiene como consecuencia la adquisición de un carácter moral. Kant sostiene que el progreso en la adopción de las máximas éticas nunca puede concluir, y es a este esfuerzo constante a lo que él denomina «virtud». Concibe a la virtud como una lucha y se refiere a ella como fortitudo moralis, como «la capacidad y el propósito deliberado de oponer resistencia [...] al adversario de la intención moral en nosotros». ${ }^{11}$. Agrega que «la virtud es la fuerza de la máxima del hombre en el cumplimiento de su deber» ${ }^{12}$. En la segunda Crítica define a la virtud como «la intención moral en combate» ${ }^{13}$, y en la Religión señala que la virtud es una «palabra que (tanto en griego como en latín) significa denuedo y valentía y, por lo tanto, supone un enemigo» ${ }^{14}$. La adopción de las máximas éticas supone, entonces, una lucha constante contra los incentivos contrarios a la moralidad, de tal modo que lo importante desde un punto de vista moral no es cumplir con el deber de manera ocasional, sino la firme determinación, a lo largo de una vida completa, de convertir a las máximas éticas en rasgos del propio carácter.

¿Cómo es posible lograr semejante transformación? En la Religión Kant sostiene que, en la medida que el deber exige una «revolución» moral, tal revolución debe ser posible. Sin embargo, nos dice: «cuando el hombre invierte el fundamento supremo de sus máximas, por el cual era un hombre malo, mediante una única decisión inmutable (y con ello viste un hombre nuevo), en esa medida es, según el principio y el modo de pensar, un sujeto susceptible del bien, pero sólo en un continuo obrar y devenir es un hombre bueno; esto es: puede esperar que con una pureza semejante del principio que ha adoptado como máxima suprema de su 
albedrío y con la firmeza de ese principio se encuentre en el camino bueno (aunque estrecho) de un constante progresar de lo malo a lo mejor» 15 .

Esta doble perspectiva sobre la «revolución» moral se debe, desde luego, a los dos puntos de vista que ineludiblemente, según Kant, tenemos que adoptar sobre nosotros mismos: en tanto que seres libres, tenemos que concebirnos como capaces de adoptar las máximas éticas mediante una «decisión inmutable»; pero, en tanto que seres susceptibles a la influencia de los incentivos de la sensibilidad, tenemos que admitir que la revolución tiene que ser gradual, ya que no podemos cambiar nuestra sensibilidad mediante una «decisión», sino solamente a través de la práctica constante de acciones éticas. Esto no significa que mientras desde el punto de vista inteligible sí es posible adoptar las máximas éticas, desde el punto de vista sensible sólo nos queda progresar. Más bien quiere decir que la autenticidad de la resolución de adoptar dichas máximas depende de la conducta efectiva y de la transformación de la sensibilidad. Por eso Kant afirma, en el pasaje anterior, que la «decisión inmutable» sólo nos hace «susceptibles al bien». La genuina adopción de las máximas éticas sólo puede tener lugar en un progreso constante, esto es, en la virtud. Aunque la adopción de una máxima es lo que él denomina una «acción interna» ( $P M D V$, Ak. VI, 218) no hay manera de llevar a cabo tal acción al margen de las acciones externas. Si bien es verdad que estas últimas no pueden ser un signo seguro de una máxima ética, sí son una condición necesaria. Alguien que está comprometido con la máxima de hacer el bien ayudará al prójimo, y si no lo hace, entonces su «compromiso» no habrá sido genuino.

La pregunta importante para los fines de este trabajo es por qué, según Kant, la práctica constante de acciones éticas puede tener el efecto de transformar el carácter de modo que se adquiera un carácter moralmente bueno. Desde luego, es posible imitar la virtud llevando a cabo las acciones que haría una persona virtuosa sin por ello llegar jamás a la virtud misma. Uno puede de manera mecánica ayudar al prójimo sin poder jamás hacerlo por los motivos que la ética exige. Es por ello que Kant sostiene que la virtud no puede basarse en el hábito (PMDV, Ak. VI, 383-384). Para que la práctica sea virtuosa no puede consistir en la mera repetición de ciertos actos externos, sino que tiene que proceder de máximas éticas con base en las cuales uno se ha propuesto actuar. El propósito de la práctica es más bien el siguiente. Por un lado, quien ha resuelto adoptar máximas éticas necesariamente tendrá que actuar en consonancia, de otro modo su resolución no habrá sido genuina. Por el otro, Kant sostiene que la práctica auténtica y exitosa de acciones éticas produce efectos en la sensibilidad. Ello es claro en un pasaje frecuentemente citado: «Hacer el bien es un deber. Quien lo practica a menudo y tiene éxito en su propósito benefactor llega al final a amar efectivamente a aquel a quien ha hecho el bien. Por tanto, cuando se dice: debes amar a tu prójimo como a ti mismo, no significa: debes amar inmediatamente (primero) y mediante este amor hacer el bien (después), sino: ¡ haz el bien a tu prójimo y esta beneficencia provocará en ti el amor a los hombres (como hábito de la inclinación a la beneficencia)!» ${ }^{16}$.

Kant sostiene que no podemos tener el deber de experimentar sentimiento alguno, ya que no tenemos control directo sobre nuestros sentimientos. Pero también nos dice que podemos llegar a producir ciertos sentimientos de manera indirecta. Alguien que practique la beneficencia por motivos éticos probablemente adquirirá con el tiempo ciertas actitudes, disposiciones y sentimientos. Tal vez adquiera mayor interés en la necesidad ajena y aprenda a reaccionar con una disposición natural a ayudar. Kant mismo pensaba que los sen- 
timientos de amor y de respeto pueden llegar a acompañar la práctica exitosa de acciones procedentes de la máxima de promover la felicidad ajena. Estos sentimientos son completamente subjetivos, lo cual significa que no nos pueden ayudar a discernir qué debemos hacer. Pero su presencia nos permite detectar con más facilidad las situaciones en las cuales cierto tipo de conducta moral es necesaria, además de ser una señal del progreso logrado en la adopción de las máximas éticas.

Regresemos ahora al ejemplo del mentiroso compulsivo. La dificultad señalada por los partidarios de la ética de la virtud es que una ética centrada en los actos particulares no hace justicia a la importancia del carácter moral. Algunos actos del mentiroso podrán ser moralmente buenos, pero su carácter no deja de ser vicioso. Sin embargo, ahora podemos ver que no se trata de una objeción contra la ética kantiana. Mientras que las acciones moralmente buenas pueden coexistir con un carácter todavía vicioso, éste no es el caso en la adopción de máximas éticas porque, si tal adopción es genuina, ello se verá reflejado no sólo en las prácticas, sino también en los sentimientos que se experimentan. Cuando el mentiroso compulsivo tiene que reprimir su deseo de mentir muestra su escaso progreso moral, esto es, su falta de virtud. Si la exigencia de la ética no fuera la firme adopción de máximas de fines a lo largo de una vida completa, su acción no sería deficiente éticamente, pero la ausencia de sentimientos apropiados hace que sí lo sea. En este sentido, Kant señala que «lo que no se hace con placer, sino sólo como un servicio compulsivo, carece de valor interno para aquel que obedece su deber con ello, y no se lo ama, sino que se evita en lo posible la ocasión de practicarlo» ${ }^{17}$. Ésta es claramente la situación del mentiroso compulsivo. Si bien los sentimientos morales no aumentan ni disminuyen el mérito moral de una acción particular basada en una máxima de deber, sí son un signo del progreso moral realizado, y su ausencia evidencia la falta de virtud. Desde el punto de vista de la ética kantiana, la acción del mentiroso de decir la verdad por deber es ciertamente moralmente buena, pero el carácter está muy lejos de ser virtuoso. Al igual que en la ética de la virtud, las acciones virtuosas sólo pueden ser el producto de un carácter virtuoso.

Los defensores de la ética de la virtud usualmente rechazan la concepción kantiana de la virtud como progreso moral y como lucha contra los incentivos contrarios a la moralidad. Con mucha frecuencia se sostiene que la virtud consiste en la armonía entre las resoluciones de la razón y los sentimientos. Kant no rechaza este ideal propiamente, sino que lo considera imposible para las seres humanos. Según su concepción de la naturaleza humana es inevitable que aun los más virtuosos puedan verse tentados a otorgarle prioridad a los incentivos del amor propio sobre los de la moralidad. Ello no significa que una persona virtuosa en esta situación actúe de manera contraria a su deber moral, pero sí implica que la ética siempre se le presentará como una exigencia. En todo caso, este desacuerdo no concierne a cuál sea el objeto principal de evaluación moral: tanto Kant como los partidarios de la ética de la virtud están de acuerdo en que tal objeto es el carácter de las personas y no sus actos particulares. El desacuerdo se refiere a las posibilidades humanas de eliminar los incentivos contrarios a la moralidad.

Otro desacuerdo importante concierne a la naturaleza misma de los sentimientos. Los partidarios de la ética de la virtud usualmente conciben los sentimientos como modos de percepción y, por tanto, como fuentes de conocimiento. Alguien que experimenta el deseo de ayudar percibe la situación en la que se encuentra como una situación en la que se debe ofrecer ayuda. El sentimiento le indica, por así decirlo, qué debe hacer. La práctica de la 
virtud consiste precisamente en la educación de los sentimientos para que nos guíen de manera adecuada. Kant, como hemos visto, pensaba que los sentimientos son meras reacciones subjetivas incapaces de ofrecernos información sobre los rasgos moralmente relevantes del mundo. Por ello pensaba también que no son susceptibles de educación mediante la razón. Sin embargo, de nuevo el desacuerdo nada tiene que ver con cuál es el objeto principal de evaluación moral. Aunque los sentimientos sean subjetivos, el progreso en la formación del carácter sigue siendo el objeto central de la ética.

Nada de lo dicho hasta aquí, sin embargo, tiene el propósito de negar que, en la ética kantiana, el mérito moral de una acción no depende en modo alguno de la virtud del carácter. La acción moralmente buena del mentiroso compulsivo sigue teniendo valor moral a pesar de que su carácter no sea virtuoso. Esto no significa que la ética de Kant se centre, por tanto, en los actos particulares. Hemos visto que está dirigida a la adquisición de un carácter moral caracterizado por su firme compromiso con las máximas éticas y la adquisición de sentimientos morales. Lo que sí significa es que se trata de una ética de la autonomía. Se sigue de la tesis de la libertad de la voluntad que aun el carácter vicioso es capaz de acciones moralmente buenas. La presencia de incentivos contrarios a la moralidad hace que las acciones éticas sean más difíciles de lo que resultan para un persona virtuosa en sentido kantiano, pero no puede hacerlas imposibles, al menos en principio. Uno de los efectos de la práctica de la virtud es precisamente lograr que la sensibilidad sea propicia a las resoluciones de la razón. Kant no puede sostener que sólo las acciones de un carácter virtuoso son tanto virtuosas como moralmente buenas porque ello sería contrario a su tesis de la libertad de la voluntad. Si fuéramos incapaces de hacer a un lado los incentivos contrarios a la moralidad y actuar por deber, tendríamos que concebirnos a nosotros mismos como determinados por nuestras inclinaciones. En mi opinión, éste es un rasgo valioso de la ética kantiana al margen de qué tesis metafísicas sobre la libertad se quieran sostener. Es importante que una teoría ética pueda otorgarle algún tipo de valor moral a las acciones moralmente correctas, hechas por motivos morales, pero que provienen de un carácter que no es virtuoso. Se trata, sin duda, de acciones valiosas, las cuales, según Kant, son los primeros pasos en el camino de la virtud.
1 Véase la introducción de Roger Crisp al libro editado por él How Should One Live? Essays on the Virtues, Oxford, Clarendon Press, 1996.

${ }^{2}$ En este trabajo me centraré en la ética kantiana.

${ }^{3}$ Fundamentación para una metafísica de las costumbres, edición castellana de Roberto R. Aramayo Madrid, Alianza Editorial, 2002. En las referencias a las obras de Kant en el texto principal aparecen las iniciales de la obra citada seguidas por el volumen y número de página de Kants gesammelte Schriften (publicados por la Preussische Akademie der Wissenschaften, Berlín) los cuales usualmente aparecen en los márgenes de las páginas en las traducciones al caste- llano, como es el caso de la edición recién citada.

${ }^{4}$ Para una explicación de por qué los sentimientos son irrelevantes para el valor moral véase de Christine Korsgaard, «From Duty and for the Sake of the Noble: Kant and Aristotle on Morally Good Action» en Stephen Engstrom y Jennifer Whiting (eds.), Aristotle, Kant, and the Stoics. Rethinking Happiness and Duty, Cambridge, Cambridge University Press, 1996).

${ }^{5}$ «Principios metafísicos de la doctrina de la virtud», en La metafísica de las costumbres, traducción de Adela Cortina y Jesús Conill, Madrid, Tecnos, 1989. 
${ }^{6}$ Algunos intérpretes han cuestionado que los deberes de justicia pertenezcan al dominio de la moral. En «La distinción entre derecho y moral en el pensamiento de Kant) (Revista Latinoamericana de Filosofia, vol. XXVII, núm. 2, 2001) sostengo que estos deberes sí son morales. Sobre este punto véase Allen Wood, «The Final Form of Kant's Practical Philosophy», en Nelson Potter et al. (eds.), Kant's $\mathrm{Me}$ taphysics of Morals. The Southern Journal of Philosophy, XXXVI, suplemento, 1997, pp.1-20; Paul Guyer, «Comments: Justice and Morality, en Potter et al. op. cit., pp.21-28; Thomas Pogge, «Is Kant's Rechtslehre Comprehensive?», en Potter et. al., op. cit., pp 161-88; Otfried Höffe, «Recht und Moral: ein kantischer Problemaufriß», en Neue Hefte fiir Philosophie, 17, 1979, pp. 1-36, y «Kant's Principle of Justice as a Categorical Imperative of Law», en Yirmiyahu, Yovel (ed.), Kant's Practical Philosophy Reconsidered, Dordrecht: Kluwer Academic, 1989.

${ }^{7}$ El encabezado de la sección VI de la Introducción a Principios metafísicos de la doctrina de la virtud dice: «La ética no da leyes para las acciones (porque esto lo hace el $I u s)$, sino sólo para las máximas de las acciones». El título de la sección siguiente (VII) dice: «Los deberes éticos son de obligación amplia, mientras que los deberes jurídicos son de obligación estricta». Kant empieza esta última sección indicando que «esta proposición es una consecuencia de la anterior», es decir, del encabezado de la sección anterior.
${ }^{8}$ Sobre este punto véase Onora O'Neill, Towards Justice and Virtue. A Constructive Account of Practical Reasoning, Cambridge, Cambridge University Press, 1996, p.186; Thomas Hill, «Kant on Imperfect Duty and Supererogation», en Dignity and Practical Reasoning in Kant's Moral Theory, Ithaca, Cornell University Press, 1992, p.148; Nancy Sherman, $M a$ king a Necessity of Virtue, Aristotle and Kant on Virtue, Cambridge, Cambridge University Press, 1997, pp.332 y 335; Allen Wood, Kant's Ethical Thought, Cambridge, Cambridge University Press, 1999 , pp. 324-325.

${ }^{9}$ Hill, op.cit., , p.156.

10 Desarrollo este tema en mi libro Virtud y justicia en Kant, México, Fontamara 2003.

" PMDV, Ak. VI, 380

${ }^{12}$ PMDV, 6, 394

${ }_{13}$ Crítica de la razón práctica, traducción de Roberto R. Aramayo, Madrid, Alianza Editorial, 2000, y traducción de Dulce María Granja, México, Universidad Autónoma Metropolitana, 2001; Ak. V, 84.

${ }_{14}$ La religión dentro de los límites de la mera razón, traducción de Felipe Martínez Marzoa, 2. ${ }^{a}$ edición, Madrid, Alianza, 1981; Ak. VI, 57.

${ }_{15}$ Religión, Ak. VI, 47-48.

16 PMDV, Ak. VI, 402.

${ }^{17}$ PMDV, Ak. VI, 484 